\title{
Opportunities and Challenges of Industrialization of Hydrogen Production from Natural Seawater
}

\author{
Austin Kingson \\ Feng Chia University \\ E-mail address austinks@hotmail.com
}

\begin{abstract}
Humans have always been looking for sustainable renewable energy, whether from coal, natural gas, hydropower, nuclear energy, solar energy, wind energy, solar thermal energy, hydrogen energy, etc., each energy has its advantages and disadvantages! 2019 Kuang et al. published "Solar-driven, highly sustained splitting of seawater into hydrogen and oxygen fuels" this paper has given the author a great level of research interest in this topic! The researcher tried to explore the challenges and opportunities that this method actually applied to mass production by thinking about various angles.
\end{abstract}

Keywords: industrialization, hydrogen, natural seawater, renewable energy

\section{INTRODUCTION}

This is an open access article under the $\mathrm{CC}-\mathrm{BY}-\mathrm{NC} \mathrm{I}_{\mathrm{BY}}^{\mathrm{NO}}$

In recent years, the world's discussion on the issue of hydrogen energy has become more and more heated. The focus of attention is mainly on hydrogen vehicles. Imagine a car without gasoline but hydrogen. The exhaust gas is water, which can also be used for power generation and drinking. This is truly renewable energy! At present, hydrogen is expensive, and every expert and scholar is looking for a suitable method to produce hydrogen at the lowest cost. The traditional process of producing hydrogen from seawater requires purification and then filtering into pure water, which is then decomposed into hydrogen and oxygen. Now, we may be able to separate directly from seawater, which can reduce more processes and costs. This article aims to conduct a preliminary assessment of the direct separation of hydrogen from natural seawater and its current and potential applications in seawater treatment and desalination, with a focus on a rigorous assessment of progress, knowledge gaps, and future research directions from a management perspective.

\section{LITERATURE REVIEW}

"Water Will Be the Coal of the Future." (Verne, 1874). Water electrolysis is the most promising method for efficient production of high purity hydrogen (and oxygen), while the required power input for the electrolysis process can be provided by renewable sources (e.g., solar or wind). There are many typical characteristics of the main electrolysis technologies, such as Alkaline electrolysis, Proton Exchange electrolysis \& Oxygen ion electrolysis (Sapountzi, F. M. et al. 2017) as per table 1 . 
Proceeding on Japan International Business and Management Research Conference (JIBM),

Vol. 1 (1), 60-68

Opportunities and Challenges of Industrialization of Hydrogen Production from Natural Seawater Austin Kingson

Table 1. The typical characteristics of the main electrolysis technologies (Sapountzi, F. M. et al. 2017).

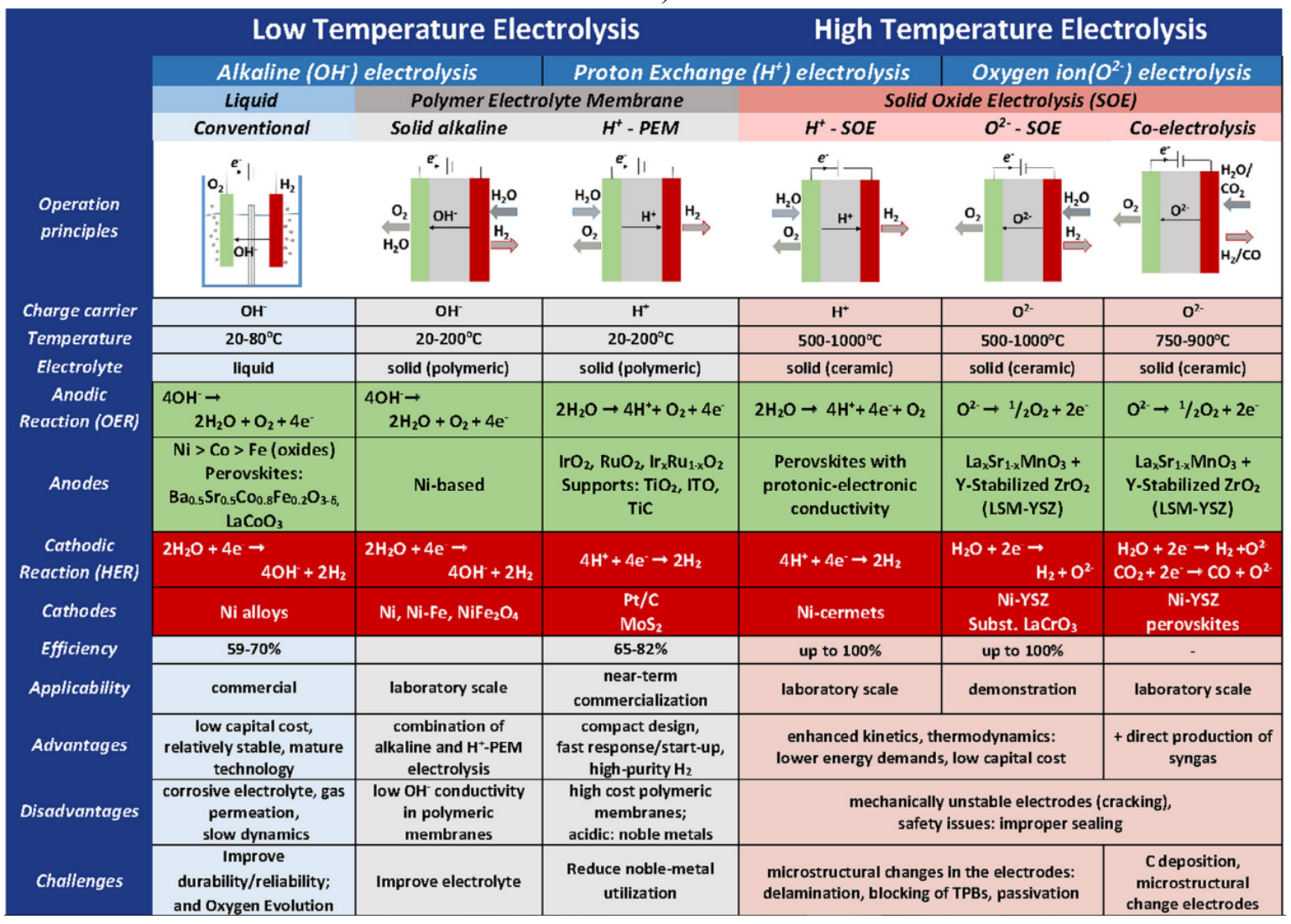

Bureau of Energy, Ministry of Economic Affairs, Republic of China (Taiwan) listed the importance of hydrogen energy in the 2007 white paper on energy technology research and development, and also proposed various possible ways and methods of hydrogen energy production. It also mentioned the use of renewable energy to electrolyze water to produce hydrogen, and this method is suitable for seawater and freshwater. Various possible ways and methods of hydrogen energy production are shown in Figure 1. 


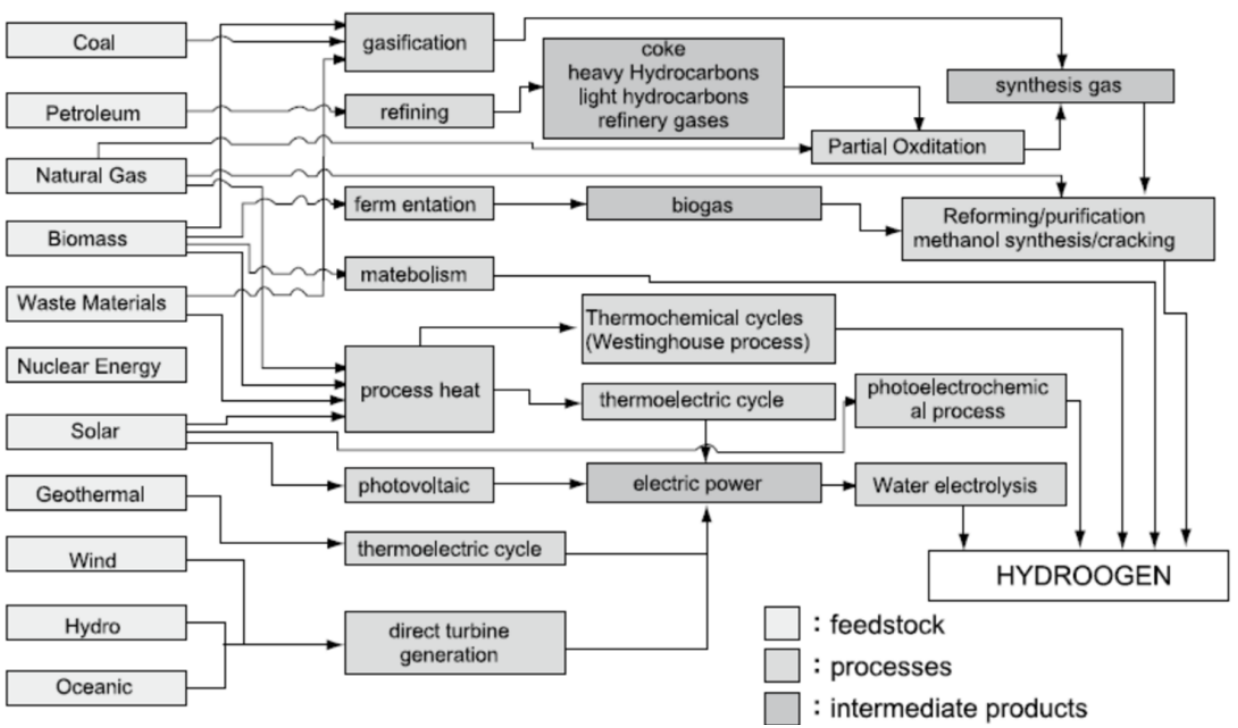

Figure 1. Various possible ways and methods of hydrogen energy production (BOE, 2007)

For example, the Offshore wind power produces hydrogen as per Figure 2.

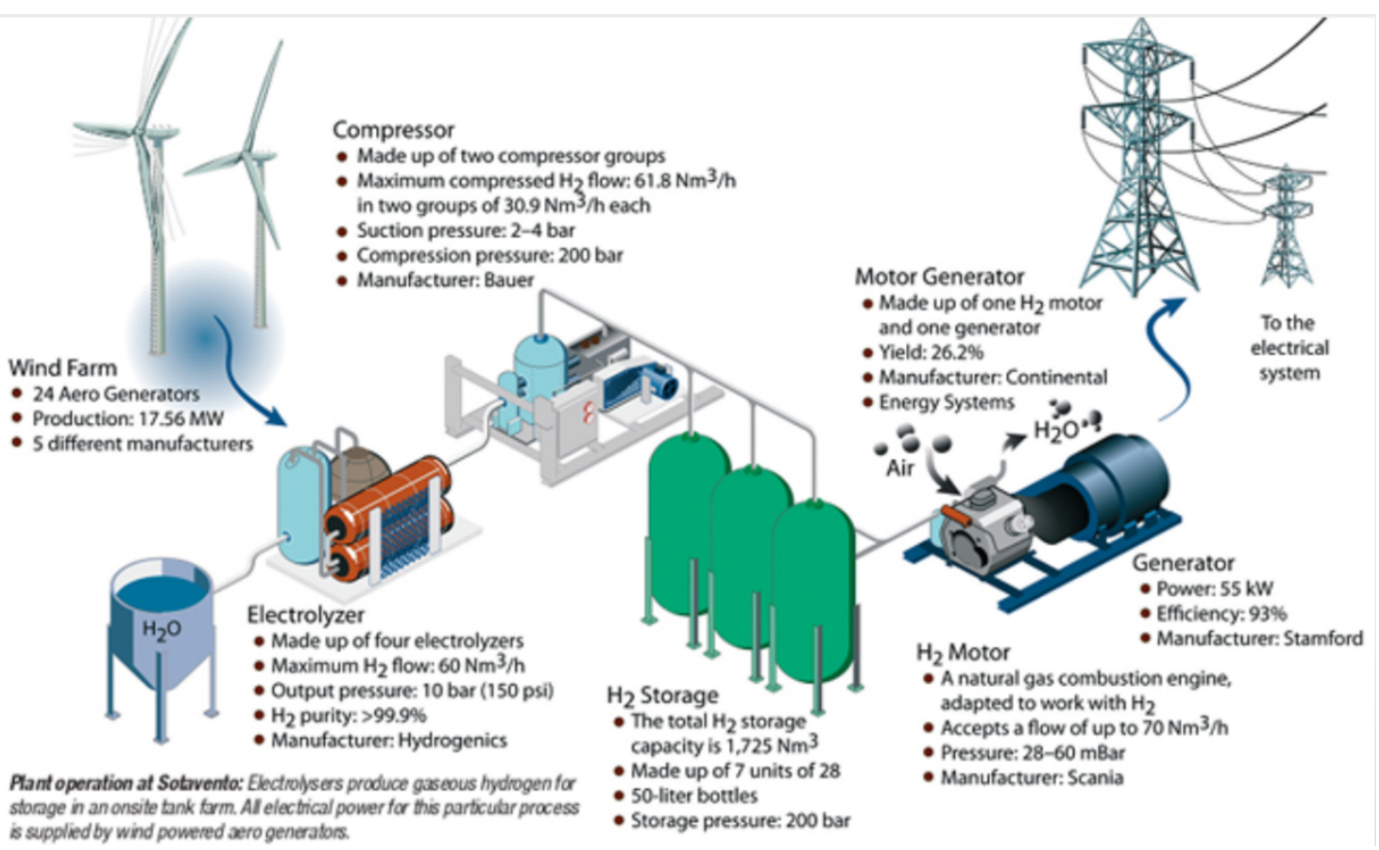

Figure 2. Offshore wind power produces hydrogen - Sotavento hydrogen-wind power plant.

(Crump, 2010).

\section{II.1 Solar electrolysis of seawater to produce hydrogen}

When the water electrolysis hydrogen production, the anode should completely avoid poisonous chlorine precipitation. Using traditional anode electrolytic seawater electrolysis of water use, with chlorine precipitation is given priority to, to avoid chlorine corrosion of equipment and the environmental pollution, the development of a chlorine oxygen inhibition anode materials is the key 
of electrolytic water hydrogen plot development technology (Zhang et al., 2009). In 2014, Xiamen University applied for a utility model patent and disclosed a device for the electrolysis of seawater by solar energy to produce hydrogen as per figure 3, which includes an electrolytic cell, an ion exchange membrane, a cathode gas collection device, a sheep pole gas collection device, and a nuclear electrolysis shop level. It also includes a seawater filtration device and solar energy. Photovoltaic cells, seawater used for electrolytic hydrogen production in electrolytic cells, seawater filtering devices are passed through the electrolytic cells, the seawater has been filtered and introduced into the electrolytic cells; a solar photovoltaic cell store is connected to a transformer, and the transformer is connected to the anode and cathode electrolytic power through the wire The seawater is used as the raw material for hydrogen electrolysis, with abundant seawater resources, wide sources, low production costs, clean and pollution-free, and can also bring additional products during the electrolysis process; the solar energy is converted into electrical energy through solar photovoltaic cells to the electrolytic power. Compared with the traditional electric power supply, it has a lower cost, sufficient power supply, pure natural, and pollution-free advantages. (CN 203976930)

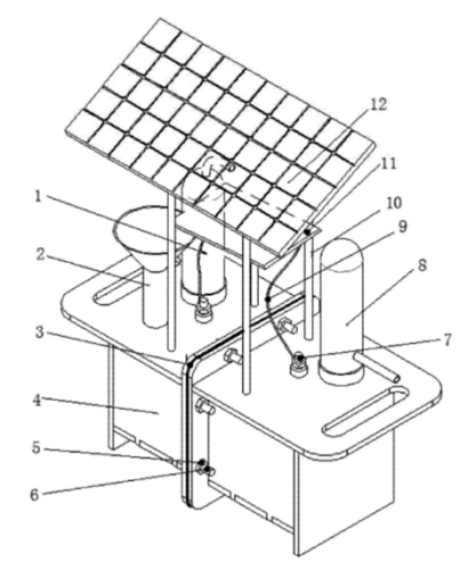

Figure 3. Solar electrolysis of seawater to produce hydrogen (CN 203976930).

\section{II.2 Photocatalytic hydrogen production}

The Photocatalyst effect is shown in Figure 4., also known as the "Honda-Fujishima effect," which was discovered by two scholars, Japan's Bunta Kenichi and Fujishima Akira. In 1967, Professor Kenichi Bunta and his graduate student Akira Fujishima discovered that using titanium dioxide and platinum as electrodes, placing them in water and irradiating them with light, even if they were not powered, they could decompose water into oxygen and hydrogen.

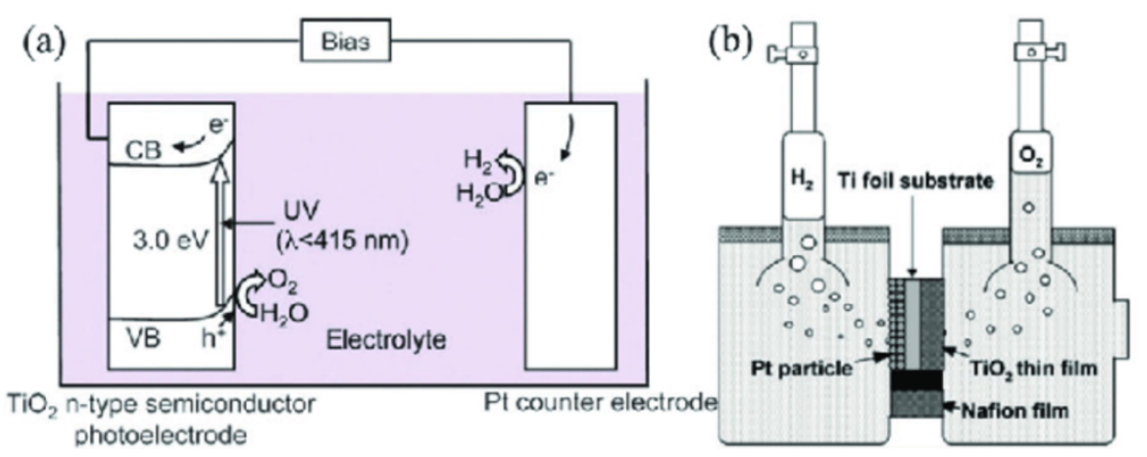

Figure 4. The Photocatalyst effect (Fujishima et al., 1972). 


\section{II.3 Hydrogen energy from the ocean}

nanomaterials make photocatalysts produce hydrogen more efficiently, as per figure 5 . Researchers have found a way to make photocatalyst composites to solve this efficiency problem. They found that the surface of titanium dioxide was chemically "etched" into the pores of the nanostructure. A nanofilm with a thickness of only one atom is laid on the surface: molybdenum disulfide by adjusting the vacancy density of sulfur atoms in the surface film. Enables photocatalysts to accept larger photon bandwidths: from ultraviolet-visible to near-infrared light, The efficiency of photocatalytic hydrolysis is nearly doubled. (Guo et al. 2018)

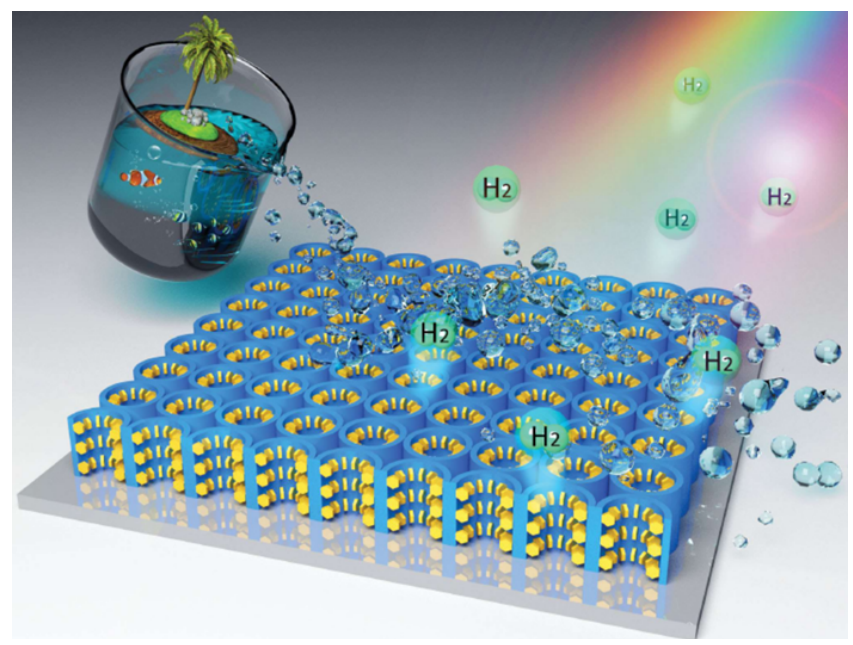

Figure 5. nanomaterials make photocatalysts produce hydrogen more efficiently (Guo et al. 2018).

\section{II.4 Photocatalytic hydrogen production}

In 2018, Li Can, a member of the Chinese Academy of Sciences' Solar Energy Research Department of the Chinese Academy of Sciences and researcher Zhang Fuxiang, made new progress in the study of the wide-spectrum catalyst $\mathrm{Z}$ mechanism for the complete decomposition of water and hydrogen. The results were published in the Joule Journal of Cell. (Qi et al., 2018) are shown in Figure 6.

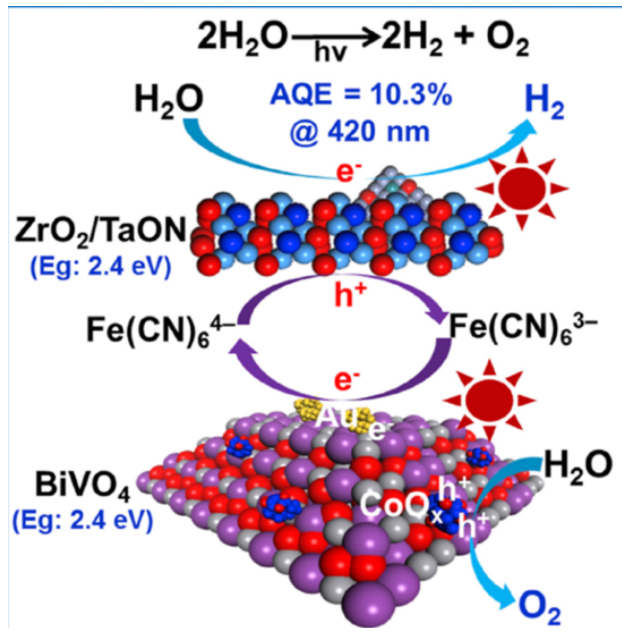

Figure 6. wide-spectrum catalyst $\mathrm{Z}$ mechanism for the complete decomposition of water and hydrogen (Qi et al, 2018). 


\section{II.5 Micro-nano structured electrode electrolysis of seawater to produce hydrogen}

$\mathrm{Ni}-\mathrm{Fe}-\mathrm{C}$ alloys have also been used for seawater electrolysis, and it was found that their activity depends on the grain size and the composition of the alloy (Sapountzi et al. 2017). Electrolysis of water to produce hydrogen fuel is an attractive renewable energy storage technology. However, gridscale electrolysis of freshwater can put heavy pressure on important water resources. The development of cheap electrocatalysts and electrodes to maintain cracking without chloride corrosion could solve water scarcity problems. A multilayer anode composed of a nickel-iron hydroxide ( $\mathrm{NiFe})$ electrocatalyst layer uniformly distributed on a nickel sulfide (NiSx) layer formed on a porous nickel foam ( $\mathrm{NiFe} / \mathrm{NiSx}-\mathrm{Ni}$ ), which has excellent catalytic activity and Corrosion-resistant alkaline seawater electrolysis operates at $1,000 \mathrm{hrs}$ of industrially required current density $(0.4$ to $1 \mathrm{~A} / \mathrm{cm} 2)$ are shown in Figure 7. A continuous, highly oxygen evolution reaction-active NiFe electrocatalyst layer drawing anodic currents toward water oxidation and an in situ-generated polyatomic sulfate and carbonate-rich passivating layers formed in the anode are responsible for chloride repelling and superior corrosion resistance of the salty-water-splitting anode. (Kuang et al. 2019)
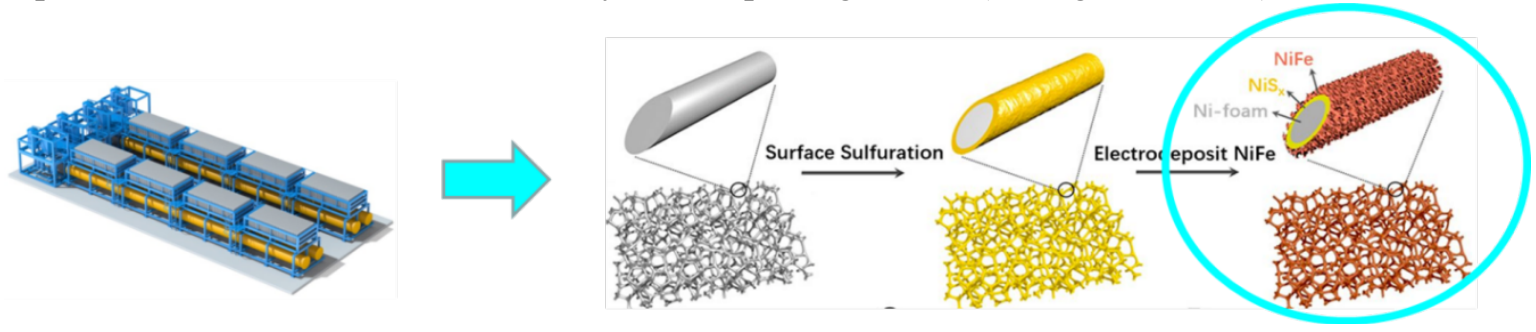

Figure 7. Micro-nano structured electrode (Kuang et al. 2019).

\section{II.6 Golden Gate Zero Emission Marine (GGZEM)}

The vessel has been dubbed the "water-go-round," a vivid illustration of how fuel cell technology works in cycles. Specifically, hydrogen can be generated from water, and then water can be generated after fuel cell use, truly achieving zero emissions and pollution-free. The all-aluminum passenger ship, designed by Incat Crowther, is 70 feet long and can seat 84 passengers at a top speed of 22 knots. (Pratt, J. W., \& Burgard, J. 2016) as per Figure 8.
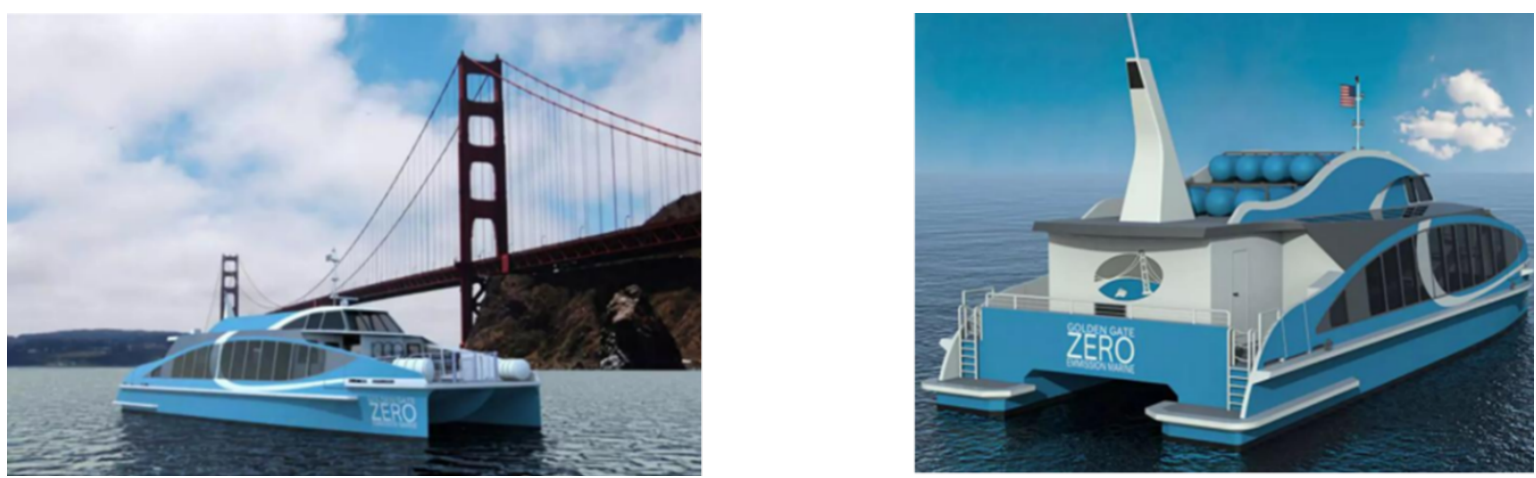

Figure 8. Golden Gate Zero Emission Marine (Pratt, J. W., \& Burgard, J. 2016). 


\section{RESEARCH METHODOLOGY}

According to the "Solar-driven, highly sustained splitting of seawater into hydrogen and oxygen fuels" thesis, the new process has been studied on an experimental scale, and the hydrogen can be directly produced by electrolysis of seawater through micro-nano structured electrodes without considering the desalination process and has a stability of thousands of hours under the current density of industrial electrolysis. This study intends to consolidate relevant literature and existing processes on seawater hydrogen production and find comparative studies based on the opportunity and challenge framework.

Document Analysis: Refers to a method that comprehensively and accurately grasps the problem to be researched by collecting relevant market information, survey reports, industry trends, and other literature data according to a certain research purpose or topic. The content of the collection should be as rich and extensive as possible, and then the data collected around should be summarized after analysis, and then the source, cause, background, impact, and significance of the event should be analyzed. Documents can be reports from government departments, research from the business sector, documentary databases, corporate organization materials, books, papers, and periodicals in the library, newspapers, and more. There are four analysis steps, namely Reading and Organizing, Description, Classifying, and Interpretation (Titscher et al. 2000)

\section{FINDING AND DISCUSSION}

Identified opportunities and challenges are as per table 2.

Table 2. Opportunities and challenges.

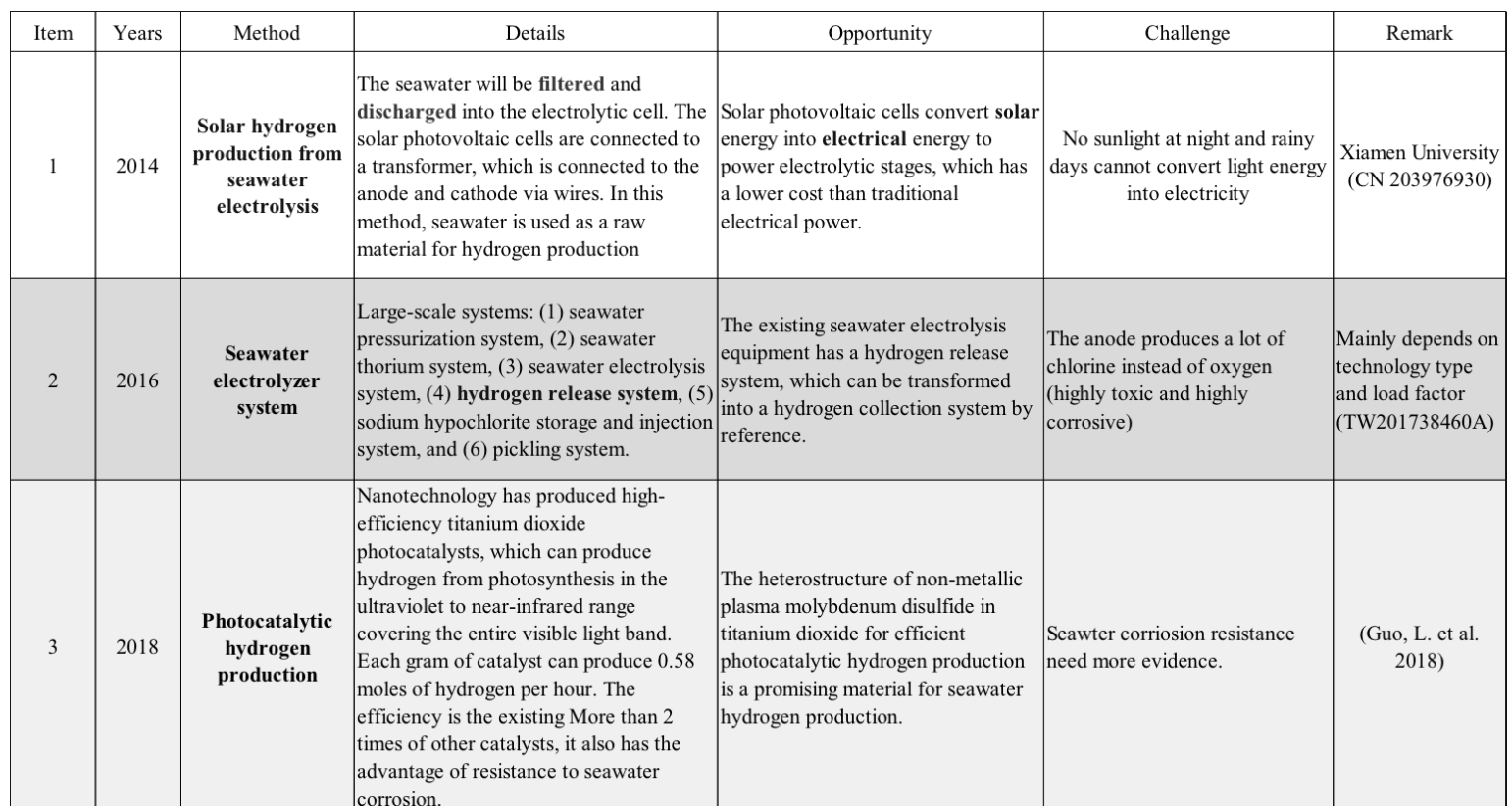




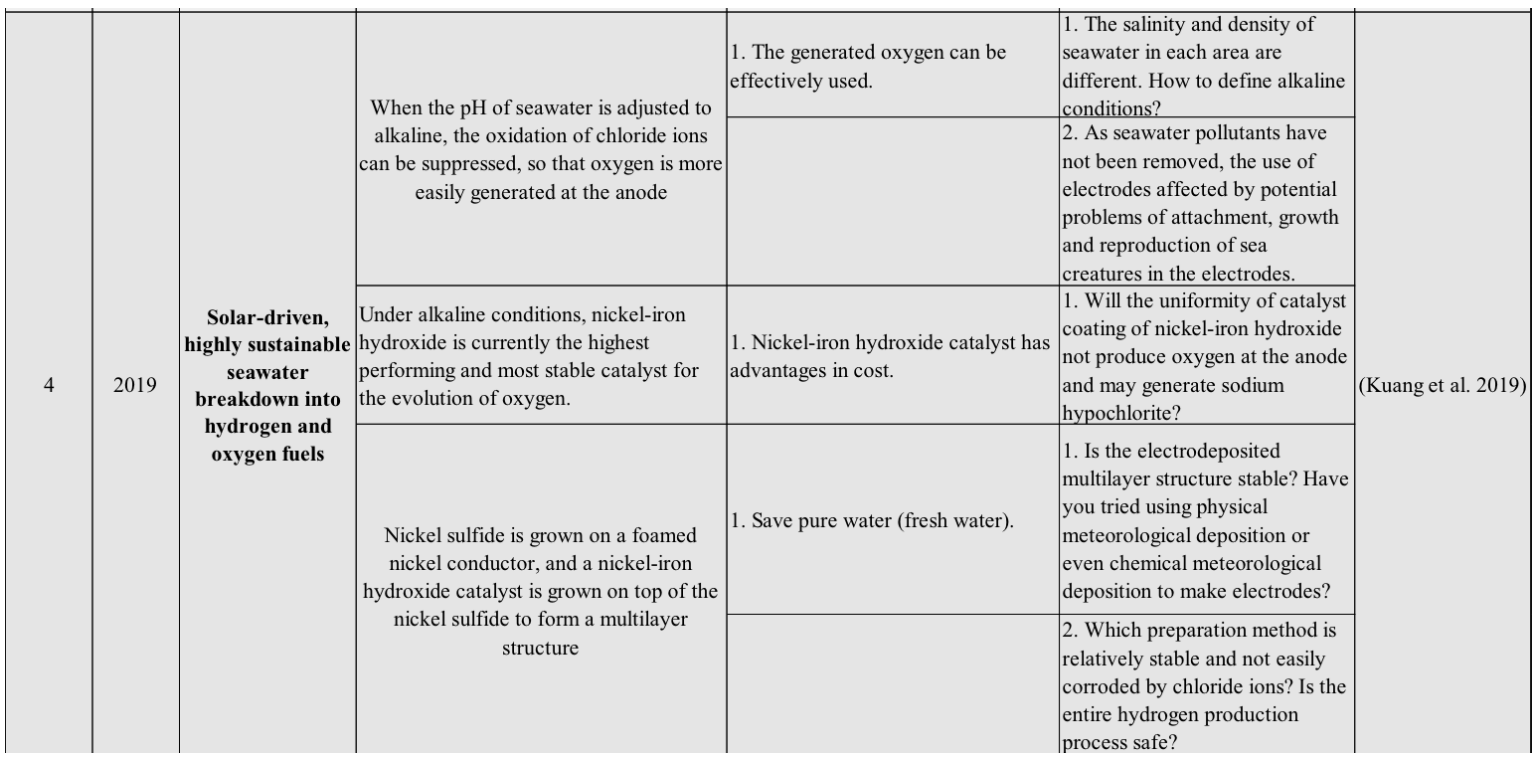

\section{CONCLUSION AND FURTHER RESEARCH}

With the continuous advancement of science and technology, we must continue to pay attention to the development of new technologies. At present, there has been a major breakthrough in the direct conversion of seawater to hydrogen and oxygen. However, we still have to measure the input costs and benefits from the perspective of management! At this stage, the use of hydrogen energy is not comprehensive. The production, storage, transportation, and application of hydrogen are still dangerous. In particular, the existing seawater electrolysis mainly involves thermal power plants drawing seawater as cooling water to cool and generate electricity. The residual heat of the sea and the marine attached organisms will enter the cooling system to adhere, grow, and multiply. This will not only reduce the efficiency of the heat exchanger but also cause blockage of the pipeline, obstruct the flow of water and cause corrosion and perforation of the pipeline. In severe cases, it will even force the unit to shut down and affect its operation. Therefore, seawater electrolysis equipment is used to produce sodium hypochlorite to inhibit and prevent the growth of marine organisms in the cooling water system pipeline. However, the application method of seawater electrolysis assigns hydrogen to flammable gas and is prone to explosion. Therefore, hydrogen is separated from seawater through a centrifugal gas-water separator and discharged to the atmosphere, instead of collecting and storing hydrogen as an energy source.

A more reasonable way is to optimize and retrofit the existing seawater electrolysis, collect the currently generated hydrogen reasonably, and gradually experiment with new technologies in small-scale tests and apply them to the existing seawater electrolysis equipment, and install a hydrogen power generation system. The generated electricity is connected to the existing power grid!

Further research is still collecting more efficient, safe, and low-cost methods; it is best to combine the existing seawater electrolysis module to modify or optimize the method, regardless of the improvement of electrode materials, cost reduction, and replacement efficiency. The most important issue is how to effectively reduce the risk of explosion in the production, storage, transportation, and application of hydrogen, and then convert the inexhaustible and inexhaustible seawater into hydrogen. As an energy source, as another effective application of oxygen, we will get rid of the hidden worry of energy depletion. 


\section{REFERENCES}

Bureau of Energy, Ministry of Economic Affairs (2007). 2007 White Paper on Energy Technology Research and Development. http://www.moeaboe.gov.tw/Policy/PoMain.aspx?PageId=energytechwhitepaper

Crump, D. (2010). Integrating Controls for Hydrogen Production. CONTROL ENGINEERING, $57(2), 53-+$.

Fujishima, A., \& Honda, K. (1972). TiO2 photoelectrochemistry and photocatalysis. Nature, 238(5358), 37-38.

Guo, L., Yang, Z., Marcus, K., Li, Z., Luo, B., Zhou, L., ... \& Yang, Y. (2018). MoS 2/TiO 2 heterostructures as nonmetal plasmonic photocatalysts for highly efficient hydrogen evolution. Energy \& Environmental Science, 11(1), 106-114.

Kuang, Y., Kenney, M. J., Meng, Y., Hung, W. H., Liu, Y., Huang, J. E., ... \& Lin, M. C. (2019). Solar-driven highly sustained splitting of seawater into hydrogen and oxygen fuels. Proceedings of the National Academy of Sciences, 116(14), 6624-6629.

Minoura, H., Oki, T., \& Tsuiki, M. (1976). CdS-electrochemical photocell with S2- ion-containing electrolyte. Chemistry Letters, 5(11), 1279-1282.

Pratt, J. W., \& Burgard, J. (2016). Zero Emissions Ferry: Using Liquid Hydrogen as an Alternative Fuel (No. SAND2016-11147C). Sandia National Lab. (SNL-CA), Livermore, CA (United States).

Qi, Y., Zhao, Y., Gao, Y., Li, D., Li, Z., Zhang, F., \& Li, C. (2018). Redox-based visible-light-driven $Z$-scheme overall water splitting with apparent quantum efficiency exceeding $10 \%$. Joule, 2(11), 2393-2402.

Sapountzi, F. M., Gracia, J. M., Fredriksson, H. O., \& Niemantsverdriet, J. H. (2017). Electrocatalysts for the generation of hydrogen, oxygen, and synthesis gas. Progress in Energy and Combustion Science, 58, 1-35.

Sultan, S., Tiwari, J. N., Singh, A. N., Zhumagali, S., Ha, M., Myung, C. W., ... \& Kim, K. S. (2019). Single atoms and clusters based nanomaterials for hydrogen evolution, oxygen evolution reactions, and full water splitting. Advanced Energy Materials, 9(22), 1900624.

Titscher, S., Meyer, M., Wodak, R., \& Vetter, E. (2000). Methods of text and discourse analysis: In search of meaning. Sage.

Verne, J. (2002). The Mysterious Island, 1874. Trans. Jordan Stump. New York: Modern Library.

Wang Qichuan, 2007 Energy Technology Development White Paper, Energy Bureau, Ministry of Economic Affairs, 2007

Zhang Zhaoxian, Cai Tianxiao (2009). Titanium Electrode Reaction Engineering, ISBN: 978-75024-4873-8, Beijing: Central South University Press 